\title{
A PRÁTICA DE GÊNEROS TEXTUAIS NA EDUCAÇÃO INFANTIL SOB O OLHAR DO DOCENTE
}

\author{
Isabela Penna Firme ${ }^{1}$ \\ Juliane Costa Pereira ${ }^{2}$ \\ Milena Almerinda Leite de Paula Watanabe ${ }^{3}$ \\ Juliane Rocha de Moraes ${ }^{4}$
}

Resumo: O presente estudo teve por objetivo analisar a possibilidade de se introduzir a prática do uso de diferentes gêneros textuais na Educação Infantil, através da realização de três projetos educativos: Produção de livro coletivo de contos (professora 1); Reescrita do conto chapeuzinho vermelho (professora 2); Produção de um jornal (professora 3). Foi conduzida uma pesquisa qualitativa em três Escolas Municipais de São José dos Campos, SP com crianças de 5 a 6 anos. Os resultados mostraram que as crianças são capazes de ir além da simples familiarização com os diversos gêneros como ouvintes, tornando-se escritoras proficientes ainda que não de forma convencional.

Palavras-chave: Educação infantil; Gêneros textuais; Formação de leitores.

\footnotetext{
1 Pós-graduação em alfabetização/Instituto Nacional de Ensino e Pesquisa - INESP, Brasil. E-mail: isabelapenna@terra.com.br.

2 Pós-graduação em alfabetização/Instituto Nacional de Ensino e Pesquisa - INESP, Brasil. E-mail: profjulianecp@gmail.com.

3 Pós-graduação em alfabetização/Instituto Nacional de Ensino e Pesquisa - INESP, Brasil. E-mail: milenakmk@hotmail.com.
} 